\title{
Entendendo a espiritualidade ${ }^{1}$
}

Making sense of spirituality

Dando sentido a la espiritualidad

\author{
Steven C. Hayes
}

[1] Universidade da Carolina do Norte em Greensboro² | Título abreviado: Making sense of spirituality | Endereço para correspondência: | Email: hayes@unr.edu | doi: 10.18761/PAC.2019.v10.n2.01

Resumo: Na linguagem comum, é feita uma distinção clara entre o mundo da matéria e o do espírito. Embora o dualismo seja tipicamente pensado como incompatível com o behaviorismo, uma análise comportamental da autoconsiência sugere que existem boas razões para uma conversa dualista. Algumas qualidades bem conhecidas tanto de aspectos espirituais humanos quanto de um Deus metafísico parecem fluir naturalmente a partir dessa análise (comportamental). Discute-se brevemente a utilização de uma faceta espiritual de self em terapia.

Palavras-chave: espiritualidade, self, contextualismo, molduras relacionais.

\begin{abstract}
In ordinary language a clear distinction is made between the world of matter and that of spirit. While dualism is typically thought to be incompatible with behaviorism, a behavioral analysis of self-awareness suggests that there are good reasons for dualistic talk. Reputed qualifies of both the spiritual aspect of humans and of a metaphysical God seem to flow naturally from the analysis. The use of the spiritual facet of self in therapy is briefly discussed.
\end{abstract}

Keywords: spirituality, self, contextualism, relational frames.

Resumen: En el lenguaje ordinario se hace una distinción clara entre el mundo de la materia y el mundo de espíritu. Aunque normalmente se piensa que el dualismo es incompatible con el conductismo, un análisis conductual de la autoconciencia sugiere que hay buenas razones para una conversación dualista. Algunas cualidades bien conocidas de los aspectos espirituales humanos y de un Dios metafísico parecen fluir naturalmente de este análisis (conductual). Se discute brevemente el uso de una faceta espiritual del self en la terapia.

Palabras clave: espiritualidad, self, contextualismo, marcos relacionales.

1 Tradução feita por Raul Vaz Manzione (raul.manzione@gmail.com) com revisão de Roberta Kovac, reproduzido com a permissão do Cambridge Center for Behavioral Studies. Publicação original HAYES, S. C. (1984) Making sense of spirituality. Behaviorism, 12, 99-110.

$2 \mathrm{Na}$ data de publicação original deste artigo (1984) o autor estava na universidade apontada. Atualmente, ele é docente na Universidade de Nevada, Reno, nos Estados Unidos. 
O propósito do presente artigo é de tentar analisar a distinção entre matéria e espírito partindo de uma perspectiva comportamental. Eu tenho três grandes motivos para tentar tal análise. Primeiro, é óbvio que preocupações espirituais exercem enorme influência sobre o comportamento de muitos, se não a maioria, dos membros de nossa cultura. Livros famosos sobre religião, misticismo, meditação e crescimento espiritual são vendidos consistentemente. Líderes espirituais são seguidos ao redor do mundo. Gastamos bilhões de dólares por ano em aprimoramento espiritual, desde terapias orientadas ao desenvolvimento espiritual até organizações religiosas. Segundo, apesar de pedidos por mudanças nessa área (Miller, 1984; Schoenfeld, 1979), houveram relativamente poucas tentativas de conduzir análises comportamentais teóricas sobre tais assuntos. As que foram realizadas focaram amplamente no desenvolvimento de superstição ou na influência moralizadora da religião organizada. (ex., Skinner, 1953). Embora estes sejam tópicos importantes, são relativamente fáceis de analisar em termos dos princípios do reforçamento ou da sobrevivência cultural. A distinção matéria/espírito por si só é mais difícil de compreender, mas é também de muitas maneiras, mais interessante. Minha intenção é focar na natureza dessa distinção como é vista na cultura Ocidental, enquanto evitarei questões sobre a influência moralizadora $e$ reguladora das práticas de organizações religiosas. Terceiro, eu acredito que uma análise comportamental da espiritualidade traz importantes resultados para uma visão comportamental sobre vários outros assuntos, incluindo autoconsciência e processos terapêuticos.

\section{Abordagens comportamentais para termos "não comportamentais"}

Existem diversas reações possíveis de behavioristas quando expostos a termos como "espírito". Uma dessas é a de rejeitá-los de imediato. Nesta abordagem, uma perspectiva comportamental poderia ser dita como tendo várias características. $\mathrm{O}$ Behaviorismo poderia ser declarado como determinista, materialista ou monista, por exemplo. Já que termos espirituais ou dualistas literalmente se contrapõem ao materialismo, monismo, e similares, eles seriam rejeitados como ilegítimos cientifica ou comportamentalmente. Embora seja uma reação lógica, não é de fato uma reação analíticocomportamental.

De um ponto de vista comportamental, rejeitar termos baseados apenas no seu significado literal apresenta dois problemas. Primeiramente, as palavras faladas ou escritas são produtos estruturais do comportamento funcional de falar ou escrever. Você pode "entender" essas frases escritas aqui embora você saiba muito pouco ou nada sobre as contingências que as fazem ser emitidas. Suas compreensões desses produtos do comportamento se devem a uma história, provida pela comunidade verbal, de reagir a eles por consenso. Por exemplo, você pode procurar palavras em um dicionário e "descobrir o que significam" baseado apenas na forma ou estrutura das próprias palavras. Uma análise estrutural desses produtos do comportamento não é o mesmo que uma análise funcional do comportamento de dizê-los ou escrevê-los.

A análise comportamental da linguagem baseia-se na compreensão dos comportamentos de falar e de ouvir ao se analisar contingências. Termos devem ser entendidos identificando as condições sob os quais são utilizados e os efeitos que seus usos têm. O significado literal é parte desse cenário (porque a estrutura da linguagem socialmente estabelecida deve participar em sua função), mas não é sinônimo dele. Portanto, rejeitar termos como irrelevante por eles serem "não-comportamentais" baseado em eles serem logica ou literalmente inconsistentes com o behaviorismo é por si só nãobehaviorista - não porque a lógica é incorreta, mas porque esse tipo de análise não é uma análise comportamental.

Existe um segundo problema relacionado com a rejeição de termos baseada em seus significados literais. Em uma visão behaviorista radical termos têm significado literal apenas dentro da estrutura da linguagem alcançada por concordância social. Termos são reconhecidos por "significar" coisas em parte por suas participações em classes de equivalência (Sidman, 1971; Sidman \& Cresson, 1973) estabelecidas pela comunidade verbal. Assim, por exemplo, o termo "matéria", por consenso, não é equivalente a "espírito". Você não pode trocar os 
termos e garantir reforçamento da comunidade verbal por fazê-lo. Em uma visão comportamental, no entanto, convenções públicas não são atalhos para a veracidade ou validade dos termos ou de observações (Skinner, 1945).

Todos nós podemos concordar que alguma coisa é algo, e mesmo assim pode não ser. A validade científica de observações não depende do consenso sobre elas, mas das contingências que controlam as observações. Existem poucas justificativas para se dizer que consenso público dentro de uma comunidade verbal comportamental garante contato com as contingências reais mais do que o consenso da cultura dominante.

Por ambas as razões, o argumento por análise literal baseia-se em uma visão não-comportamental da análise de termos psicológicos. Uma análise comportamental pode ser feita de qualquer termo, mesmo daqueles que são literalmente incompatíveis com o behaviorismo (ex., ver Hayes \& Maley, 1977). Essa é minha intenção nesse artigo.

Uma segunda reação que behavioristas às vezes fazem a termos "não-comportamentais" é mais satisfatória, mas não é, em última análise, adequada. Quando confrontados com ter de explicar o uso de termos difíceis ou regras, behavioristas frequentemente apontam para o condicionamento social imediato que deu origem ao uso de tais termos pelo indivíduo ou o controle por tais regras. Poderíamos, por exemplo, falar de modo geral sobre como uma criança passou a usar a palavra "espírito" baseado nas contingências empregadas pela família ou pela igreja. De maneira mais abstrata, poderíamos nos perguntar sobre as contingências de sobrevivência cultural que poderiam ter favorecido o uso de tais termos. Ambas as condutas soam comportamentais, e em muitos casos podem ser totalmente adequadas às demandas analíticas da situação. Se, no entanto, o termo possuir propriedades de tato, essas duas condutas não são adequadas porque nós devemos, então, também entender as condições físicas reais que deram origem ao termo.

Uma característica essencial de muito do comportamento verbal é a maneira que é controlado por (e de que pode formar equivalência de estímulos com) elementos nos ambientes naturais e sociais. Muito do comportamento verbal humano é, até certo ponto, um tato. Sob essas condições, com- preender o contexto ${ }^{1}$ é crítico. Para entender o termo "maçã" não é suficiente falar amplamente sobre condicionamento social ou sobrevivência cultural. Temos também de lidar com maçãs. Na medida em que é um tato, maçãs são pré-requisitos necessários para a maneira que usamos o termo "maçãs".

O mesmo pode ser verdadeiro na distinção matéria/espírito. É claro, behavioristas (enquanto se comportando como behavioristas) não acreditariam que o dualismo é literalmente verdadeiro. O perigo é se presumir, baseado apenas no nosso consenso, de que o dualismo é incorreto e que falar sobre espiritualidade pode não ser um tato. Isso leva de volta para a armadilha da literalidade recém discutida. A distinção matéria/espírito é em partes ora um tato, ora não. Consenso não decidirá isso para nós. Uma tribo primitiva pode tatear todos os aviões como "Deus". O fato de que isso está em desacordo convencional com nosso ponto de vista não o torna menos tato. Ademais, caso fôssemos estudar essa comunidade verbal, não poderíamos entender "Deus" sem lidar com o fenômeno físico dos aviões.

Portanto, uma terceira abordagem é tentar identificar de maneira mais abrangente as fontes de controle sobre a origem de tal diálogo para identificar as condições físicas reais nas quais tais conceitos e distinções poderiam surgir e as funções às quais poderiam servir. Procurar por eventos que poderiam primeiro ter sustentado a distinção matéria/espírito parece especialmente razoável ao se perceber que as distinções matéria/espírito são quase universais na cultura moderna. Como foi a primeira vez em que matéria se distinguiu de espírito? Se pudermos prover estímulos físicos plausíveis que ocasionam a palavra "espírito", então pode ser um tato. Se não, então esse pode ser mais um termo mentalista devido puramente às convenções sociais-verbais. A estratégia que pretendo adotar nesse artigo é procurar por eventos físicos reais que ocasionam a distinção matéria/espírito e ao mesmo tempo reconhecendo plenamente que apenas porque dispomos de um termo para algo não significa que ele existe literalmente.

1 Nota do tradutor: Stimulus situation, no original. 


\section{O que é "espírito"?}

Se você quiser entender o que um termo "significa”, é razoável (mas não fundamentalmente satisfatório) começar com o que a concordância social tem a dizer, isso é, procurar no dicionário. Como já discutido anteriormente, qualquer explicação funcional deve envolver uma explicação estrutural, de forma que definições formais possam delinear o que deve ser englobado. As seguintes definições podem todas ser encontradas no Dicionário de Inglês Oxford. O Dicionário de Inglês Oxford define "espírito" como um "ser imaterial ou incorpóreo" e como um "ser ou inteligência distinto de qualquer coisa física." ${ }^{2} E m$ sua essência, então, é dito que o espírito pode ser conhecível, mas, ainda assim, dito como não sendo nem material nem físico. Se você procurar por "matéria" você irá encontrar que a palavra é relacionada à madeira ou materiais de construção. Matéria é "a substância de que algo é feito". Então matéria é a "coisa-substância". Uma "coisa" é definida como "o que é ou pode ser um objeto de percepção, pensamento ou conhecimento." A palavra "objeto" vem de uma palavra que significa "arremessar". É uma "coisa arremessada aos sentidos ou à mente". Não podemos ir mais além, pois essa definição nos leva de volta à "coisa". Se voltarmos e pegarmos a palavra "físico" também não poderemos ir mais além. A palavra "físico" vêm de uma palavra para natureza (portanto a ciência da Física) e é definida como "de ou pertencente ao mundo dos fenômenos dos sentidos; matéria."

Juntando todas essas definições, caso fôssemos usar as palavras literalmente, nós iremos primeiro buscar por eventos que não são publicamente observáveis. "Espírito", além disso, não poderia ser qualquer evento privado por não ser experienciável como uma coisa ou objeto (como a maior parte dos eventos privados certamente são) embora deva, de alguma maneira, ser experienciável se o termo estiver sob controle de qualquer evento que seja.

2 Nota do tradutor: ao procurar no Dicionário Houaiss da língua portuguesa, a palavra "espírito" apresenta algumas definições, como "a parte imaterial do ser humano; alma", também como "substância imaterial, incorpórea, inteligente, consciente de si" e como "princípio vital, superior à matéria". A definição transcrita pelo autor do Dicionário de Inglês Oxford foi mantida.

\section{A análise}

Por onde poderíamos começar a entender comportamentalmente um conceito tão estranho como "espírito"? Em primeira vista, este termo parece ilógico e certamente não se parece em nada com o que conhecemos no mundo do comportamento. Essa é a aparência, mas eu quero argumentar que ela não é verdadeira. Existe um evento comportamentalmente razoável que corresponde muito bem às características mencionadas. Para vê-lo nós teremos de examinar uma área bem óbvia: o comportamento verbal.

Deixe que a palavra "ver" represente todas as coisas importantes que fazemos em relação ao mundo (sentir, mover etc.) Para organismos nãoverbais existe apenas o mundo e o ver. Ver é controlado totalmente pelas contingências diretas (de sobrevivência e de reforçamento). Ver é simplesmente uma resposta à essas contingências não-arbitrárias.

Isso muda com o advento do comportamento verbal. De acordo com a análise comportamental tradicional se adiciona algo a mais, chamado de autoconsciência ou autoconhecimento. Skinner descreveu desta forma:

\footnotetext{
"Existe uma... diferença entre se comportar e relatar que alguém está se comportando ou relatar as causas do comportamento de alguém. Ao arranjar condições sob as quais a pessoa descreve o mundo público ou privado em que vive, é gerado uma forma muito especial de comportamento chamado saber... O autoconhecimento é de origem social." (1974, p. 30).
}

Em outras palavras, a comunidade verbal estabelece contingências arbitrárias adicionais para um comportamento que dificilmente emergiria de alguma outra forma: não apenas ver, mas sim o que chamaríamos de "ver o ver" ou autoconhecimento. Supostamente isso acontece através de algumas coisas como perguntas do tipo "O que aconteceu com você ontem? O que você viu? O que você comeu?" e assim por diante. Disso emerge uma tendência generalizada de responder discriminativamente ao próprio comportamento de forma a estabelecer uma correspondência a esse comportamento e o 
comportamento verbal e, desse modo, fornecer à comunidade verbal acesso ao que vemos.

Conforme Skinner diz, "É somente quando o mundo privado de uma pessoa se torna importante para as demais é que ele se torna importante para a própria pessoa". (Skinner, 1974, p. 31).

Até aqui, nada de fato implica espiritualidade. O mundo dos sentidos ("ver") é explicitamente o que é não espiritual. É como uma "coisa" (thing-li$k e$ ) no sentido de que agora nós vemos isso, agora aquilo, então há uma distinção entre isso e nãoisso. Tal distinção é a condição para coisas serem coisas. ${ }^{3}$ Ver o ver não é tão como uma coisa - mas também é experienciável como uma coisa. Por exemplo, nós dizemos que estamos conscientes, sonolentos ou hipervigilantes. Nosso ver o ver muda; ele vai e volta.

Essa qualidade de distinção dentro do mundo do ver o ver significa que ele é experienciável como uma coisa e, portanto (de acordo com o dicionário), não pode ser aquilo do que o espírito é feito.

O que parece que faltou na maioria das explicações comportamentais é que ver o ver não é tudo que explica a autoconsciência. É também crítico para a comunidade verbal que esse comportamento ocorra de um certo ponto de vista, lócus ou perspectiva consistente. Isso é, nós (a comunidade verbal) não devemos apenas saber que você vê e que você vê o que você vê, mas que você vê que você vê. Relatos de ver (ex., ver o ver) devem partir do ponto de vista de você. Esse comportamento pode emergir de várias maneiras. Primeiro, palavras como "aqui" e "ali" são adquiridas e elas não se referem a algo em específico, mas a uma relação ao ponto de vista da criança. Por exemplo, "lá" é qualquer lugar que não "aqui" e "aqui" é sempre "desse lócus ou ponto de vista.". Segundo, crianças são ensinadas a distinguir suas perspectivas das dos outros. Crianças pequenas tem grande dificuldade com a questão da perspectiva. Por exemplo, crianças pequenas sen-

3 Hineline (1980) e outros avisaram sobre o perigo em se enxergar o comportamento como uma coisa. É melhor considerado como um verbo do que um substantivo. Para nossos propósitos, no entanto, coisas são eventos que nos permitem ver que eles são "isso" e "não aquilo". Correr não é falar, por exemplo, no sentido de que mesmo verbos são coisas. No uso comum, no entanto, eu concordo fortemente com a análise de Hineline. tadas de frente a um boneco irão, quando solicitadas, dizer que o boneco vê o que elas estão vendo. Gradualmente, no entanto, um senso de perspectiva emerge. Uma criança aprende que o que ele ou ela vê é visto de uma perspectiva. Similarmente, uma criança pequena, quando perguntada sobre o que comeu no café da manhã, pode vir a responder com o que na verdade o irmão dela comeu, mas uma criança mais velha não fará o mesmo erro. Através de correção ("Não, isso foi o que seu irmão comeu. O que você comeu?") a criança deve aprender a ver vendo de um lócus consistente. É também possível, por fim, que um senso de lócus emerja através de um processo de eliminação ou de extensão metafórica. Suponha que uma criança possa dar respostas corretas à pergunta "o que você $\mathrm{x}$ ?", onde " $x$ " equivale a ampla variedade de eventos como comer, sentir, assistir e assim por diante. Os eventos mudam constantemente. Nos nossos termos, ver e ver o ver muda. Só o lócus que não. Portanto, a consistência entre a palavra "você" em tais perguntas e o comportamento não é de ver ou ver o ver, mas o comportamento de ver que você vê a partir de um lócus ou perspectiva particulares. Portanto, em um sentido real, "você" é a perspectiva.

O comportamento de ver o ver de uma perspectiva é um comportamento muito curioso. Para a pessoa se engajando nesse comportamento, não é verdadeiramente possível vê-lo como um objeto. É apenas experienciável em seus efeitos, às sensações associadas à ele ou como um tipo de pós-imagem efêmera quando tentamos agarrar e observar diretamente. Caso fôssemos ver nossa própria perspectiva (ex., como um objeto), de qual perspectiva veríamos?

Uma questão análoga à essa (que não é diretamente a mesma coisa, mas pode servir convenientemente como metáfora) pode nos ajudar a visualizar essa questão.

Considere o evento de observar a partir dos olhos de outra pessoa. É de fato impossível observar a observação dos olhos de outro onde o objeto é o mesmo que olhar para o objeto. Se você pudesse dar um salto ao seu lado, mais rápido que a velocidade da luz, você poderia ver a si mesmo olhando (como se você tirasse uma foto), mas você estaria fazendo-o de uma perspectiva diferente. Seus olhos estariam em outro lugar. Se você olhar em um espe- 
lho você vê a si mesmo-você está, essencialmente, olhando de volta a si mesmo - mas o que você está vendo não é a mesma perspectiva que olhando de seus olhos. Não importa aonde você estiver, seus olhos estarão lá. Você de fato não pode ver sua perspectiva e ao mesmo tempo ver a partir dessa perspectiva. Para ver a perspectiva, a perspectiva deve mudar. (Essa mesma questão básica já foi amplamente discutida na literatura de filosofia da ciência aonde filósofos apontaram para o fato de que premissas de uma teoria não podem ser explicadas pela própria teoria).

O senso de perspectiva ou lócus como um evento comportamental é igual ao do olho como um evento estrutural. Sem dúvida a maior parte de vocês já experienciou o fenômeno de estarem falando e de repente verem que você está falando e então perceber que em certo sentido você está vendo a si mesmo falando. Nesse mesmo instante, você percebe que você está um passo atrás do você que viu a si mesmo falando. Esse tipo de corrida atrás do rabo é por fim sem êxito tanto quanto é fascinante. Simplesmente parece não existir maneira de ver sua própria visão-a-partir-da-perspectiva sem fazê-lo de uma perspectiva agora-alterada. Isso significa que você-como-perspectiva não é experienciável por inteiro como uma coisa ou objeto pela pessoa observando dessa perspectiva.

A comunidade verbal utiliza a palavra "você" de diversas maneiras, é claro. Às vezes pode significar "você" como um sistema físico, como "eu vi você dormindo ontem. " Mais frequentemente, no entanto, parece se referir explicitamente a você-como-perspectiva. Considere a seguinte questão: "Se você perdesse seus braços e pernas, você ainda seria você? " Dada a natureza da pergunta ("Você como estrutura física") a questão poderia ser razoavelmente respondida com um "não". Se a natureza da pergunta, no entanto, se refere ao você-comoperspectiva verbalmente estabelecido, então a resposta óbvia é sim. De fato, nossos corpos mudam constantemente, mas ainda somos ditos sermos a mesma pessoa.

O mesmo princípio se aplica a qualquer aspecto de nós que possa ser tido como um objeto, tal como nossos pensamentos, emoções, predisposições comportamentais e assim por diante. Se lhe pedirem para lembrar sobre como era ter
10 anos de idade - para lembrar sobre explorar o mundo nessa idade - e lhe perguntarem "Esse era você então?" ou "Lá no fundo, você que está aqui agora é o mesmo você que estava lá então?" e de novo a óbvia resposta é sim. Logicamente, isso não é de todo verdade em termos de você-como-objeto. Seus pensamentos são diferentes, seu comportamento é diferente, seus sentimentos são diferentes e assim por diante. Mas agora observe a sentença anterior. Embora soe normal, perceba que o "você" nessa frase se refere a algum tipo de agente independente de todas as coisas sobre você. Quando eu digo "seu corpo" é como se você possuísse um corpo - não que você é seu corpo. Para um behaviorista (ou qualquer materialista) isso parece literalmente impossível. No entanto, a comunidade verbal não está fazendo declarações científicas em tais frases. Em vez disso, o "você" referido à comunidade verbal está realizando o ver o ver a partir de um dado contexto. Enquanto esse próprio comportamento não mudar, você ainda é você. $O$ que você vê irá mudar drasticamente - seu corpo vai envelhecer, seus pensamentos irão mudar - mas o lócus ou contexto de autoconhecimento não irá nem poderá (mudar).

Você nunca se viu vendo de uma perspectiva diferente da sua própria. Você pode até imaginar como é fazê-lo (isso pode até ser importante de forma a adquirir um senso de perspectiva), mas mesmo se você imaginar isso tudo, você imagina tudo isso da sua perspectiva de eu. Portanto, embora o conteúdo da sua vida possa mudar, você-como-perspectiva não pode. ${ }^{4}$ Se fôssemos capazes de fazê-lo, nós não poderíamos ter respostas geralmente confiáveis à perguntas como "o que você fez ontem?" Se você pudesse ver eventos de um lócus diferente, você não poderia mais ser você. Uma comunidade verbal que permitisse qualquer outra coisa iria desmoronar ao caos.

4 Essa distinção é crucial para o procedimento conhecido como "treinamento est" (Erhard Seminars Training). Pessoas que passaram por esse treino reconhecerão a dívida intelectual que o presente argumento deve a ela e eu gostaria de formalmente reconhecer tal dívida. 


\section{Implicações para a espiritualidade}

Espírito é definido como um ser "imaterial"; matéria é a substância das coisas. Espírito é, portanto, um ser não-experienciável como uma coisa. Você-como-perspectiva parece se encaixar nessa definição razoavelmente bem. Como discutido anteriormente, a essência de uma coisa ou objeto é "isso-não aquilo". Para vermos uma coisa nós temos também de ver "não-coisa". Portanto, todas as coisas devem ser finitas-elas devem ter bordas ou limites. São as bordas ou limites que nos permitem ver a coisa. Se uma coisa estivesse absolutamente em qualquer lugar não poderíamos vê-la como uma coisa. Para a pessoa que a experiencia, vocêcomo-perspectiva não possui extremidades estáveis ou limites - não é totalmente experienciável como uma coisa. A perspectiva é precisamente o aspecto em que as coisas são contidas. Assim que a perspectiva é vista como conteúdo, de qual perspectiva ela é vista? A perspectiva deve dar um passo atrás. Parece, então, plausível que a distinção matéria/espírito tenha em sua origem a distinção conteúdo/ perspectiva estabelecida como um necessário efeito colateral da linguagem. Bem literalmente, pode ser que o comportamento verbal deu à humanidade uma alma.

A distinção matéria/espírito é antiga e se originou bem antes da perspectiva científica emergir. Ao invés de rejeitar essa distinção, a presente análise sugere que essa é uma distinção bastante razoável e sofisticada - permitindo-nos usar a linguagem aonde o uso comum da linguagem (tatear eventos que são experienciáveis como coisas) não se aplica prontamente. Obviamente, a presente análise sugere que a perspectiva é de fato uma coisa - é um comportamento socialmente estabelecido de importância para a comunidade verbal. Nós podemos rapidamente examinar outras pessoas e ver seus "comportamentos-de-você-como-perspectiva" como uma coisa. Mesmo ao fazer isso, no entanto, nós estamos observando isso de nosso próprio comportamento de "você-como-perspectiva" e esse contexto ou perspectiva não é por nós mesmos experienciável como uma coisa por nós mesmos. Portanto, o comportamento de você-como-perspectiva pode ser uma coisa estável somente quan- do é outro alguém sendo observado. Para a pessoa que o está fazendo ele não pode ser observável e descrito da mesma forma como todos os outros eventos são observáveis e descritos.

Falar dessa forma nos ajuda a compreender algumas das características que dizem ser parte do mundo do espírito. Considere as características da imortalidade temporal ou infinitude física. Isso significa eterno; sem limite ou fim; sem fronteiras. Até onde você sabe você nunca esteve em outro lugar senão o que você-como-perspectiva também não esteve. Não há nada que você já fez ou sentiu, que saiba sobre que não estivesse dentro do contexto chamado você. No campo da experiência (não da lógica), tanto quanto você sabe, você não tem limites e não tem fim. Pelo menos você nunca experienciou quaisquer limites, ou barreiras ou fins que você conheça por definição. Se você sabe sobre isso, você estava lá para saber sobre isso.

Da mesma maneira também ficam claros outros aspectos da espiritualidade. Comumente se acredita que o lado espiritual da humanidade participa no divino. Por exemplo, diz-se que humanos são feitos à "imagem e semelhança de Deus". Vamos agora examinar as características de um Deus metafísico e ver como isso se relaciona ao você-como-perspectiva. Considere os seguintes termos que já foram usados para descrever a Deus.

\section{a. Absoluto, Único, Identidade Perfeita, União.}

Você pode experienciar diretamente a não-divisão em sua própria perspectiva. Reconhecemos, no entanto, que outras pessoas existem, então enquanto participamos de ou modelamos uma união irrevogável, nós geralmente não a reivindicamos a nós mesmos. A "Identidade Perfeita" de Deus é, em certo sentido, uma extensão lógica de nossa experiência de nós mesmos como contexto ou pura perspectiva.

\section{b. Nada/Tudo}

Essa visão de Deus mais Ocidental é facilmente compreendida da mesma forma. Você não é experienciável como uma coisa. Portanto você é uma "não coisa" (a palavra "nada" era 
originalmente escrita como "não coisa" ${ }^{\text {. Os }}$ únicos eventos que não possuem extremidades (eles não são coisas) são nada e tudo. Experiencialmente, nós somos tudo/nada.

\section{c. Imutável, Eterno, Onipresente}

Já que você-como-perspectiva pode reter conteúdo, mas não é por si só experienciado como conteúdo, não há nada para mudar sobre vocêcomo-perspectiva. Você foi você por toda sua vida. Você está em todos os lugares que já esteve. As palavras listadas aqui são perfeitamente boas maneiras de dizer isso. Obviamente, no entanto, reconhecemos que de fato morremos, $\mathrm{e}$ mudamos; que estamos aqui e não lá. Portanto existe uma tensão lógica-indutiva que dificulta a verdadeira aceitação do que nossa experiência de você-como-perspectiva nos diz. Deus é uma entidade sem quaisquer dessas contradições.

\section{d. Amor}

Quando pessoas falam que "Deus é amor" elas geralmente se referem à qualidade de aceitação absoluta de um Deus metafísico. Em certo sentido, Deus é visto como o contexto de todos os contextos. Perceba que você-como-perspectiva aceita perfeitamente qualquer conteúdo. Dor e prazer são igualmente bem-vindos. $\mathrm{O}$ fato de não gostarmos de dor (e assim por diante) é mais conteúdo que também é igualmente bemvindo. Uma metáfora para a perspectiva pode ser um piso que se estende sem fim por todas as direções. Existirá algo feio nesse chão bem como existirá algo belo. Amor é uma palavra razoavelmente boa para isso em nossas vidas pessoais (quando alguém de fato aceita "quem nós somos" por completo), e por extensão o contexto de todos os contextos é, nesse sentido, amável em sua essência.

O que estou afirmando é que as qualidades de um Deus metafísico podem ser entendidas como uma extensão metafórica das qualidades experienciáveis do comportamento de ver-que-está-vendo-

5 Nota do tradutor: Em inglês: nothing e no thing. No português, no entanto, a palavra "nada" vêm do latim da expressão [res] nata, que significa "coisa nascida". de-uma-perspectiva. Se a alma é um subproduto da linguagem, então um Deus metafísico também o é quando visto dessa perspectiva. ${ }^{6}$

Análises comportamentais anteriores na área da religião tenderam a enfatizar os aspectos moralizantes da religião, ou os possíveis comportamentos supersticiosos que ela traz. Tais instituições poderiam ter se desenvolvido de qualquer forma, sem a experiência de aspectos espirituais (no sentido utilizado aqui), mas parece que sua universalidade é mais facilmente explicada por uma fonte original comum. $\mathrm{O}$ uso avançado da linguagem, então, pode ter criado o palco para o dualismo, espiritualidade $e$ religião por sua distinção inerente ou "dualismo" entre conteúdo e perspectiva. A maior parte das religiões possuem tradições místicas e espirituais em adição às suas regras e condutas morais. Paradoxalmente, a espiritualidade pode ser a fonte de muitas dessas regras, de modo que pode ser mais fácil entrar em contato com as contingências (e então gerar regras sobre elas) de um tópico espiritual, o qual agora irei falar sobre.

\section{Por que a espiritualidade pode ser importante?}

Uma coisa é prover, como espero que eu tenha feito, uma explicação comportamental plausível da distinção espírito/matéria. Outra é explicar por que tal distinção deve ser assunto de tanta atenção. Existem fortes tradições culturais que sustentam a busca por nossas dimensões espirituais. O que explica isso?

Talvez, a partir dessa análise, uma dica seja de que apenas organismos verbais podem estabelecer uma distinção matéria/espírito. No entanto esse próprio sistema verbal cria outros problemas. Existe uma crescente literatura que sugere que organismos verbais entram em contato com o mundo

6 Essa afirmação, e a um certo ponto esse artigo como um todo, pode parecer a alguns como sacrílego. Não é de meu interesse, no entanto, literalmente dizer que Deus ou espírito de uma visão religiosa não existe independente da humanidade. Pelo contrário, Deus pode ter criado os próprios mecanismos que estou descrevendo que o fazem espiritualmente conhecível. O presente artigo apenas denota falar sobre espiritualidade dentro do jogo que chamamos de ciência. 
de um modo diferente de que organismos nãoverbais. (Baron \& Galizio, 1983; Hayes, 1989). Um intrigante achado em especial é de que o controle por regras ou estímulos verbais produz uma insensibilidade a mudanças nas contingências diretas ou naturais (Hayes, Brownstein, Zettle, Rosenfarb, \& Korn, 1986; Hayes, Greenway, Brownstein, Haas, Russell, Squittiere, Rosenfarb, Zettle, Herbert, Herbert, Meinhold, \& Thompson, 1984; Matthews, Shimoff, Catania, \& Sagvolden, 1977; Olson \& Hayes, 1984; Shimoff, Catania, \& Matthews, 1981). Podem haver diversas fontes de controle sobre esse efeito (Hayes et al., 1984), mas a base fundamental das diferenças entre o controle por estímulos verbais e o controle por estímulos não-arbitrários deve ser de que regras possuem seus efeitos discriminativos (ou outros) baseados não apenas em treino direto, mas também em sua participação em classes de equivalência ou outras classes simbólicas estabelecidas pela comunidade verbal. (Hayes, 1989; Hayes, 1986; Hayes et al., 1984). Em outras palavras, quando nosso comportamento é controlado por regras ele é controlado pelos efeitos indiretos de estímulos simbólicos (ou "conceitos") por conta de suas naturezas conceituais ou simbólicas. Esse é fundamentalmente um tipo diferente de controle de estímulos e expande o impacto da comunidade verbal em nosso comportamento, mesmo quando as contingências diretas seriam mais eficientes em guiar nosso comportamento. A resultante insensibilidade às contingências diretas pode produzir grandes benefícios à nossa cultura, mas também grandes custos ao indivíduo. Por conta de nossas habilidades verbais estamos constantemente analisando, explicando, entendendo, e assim por diante, mesmo quando as contingências diretas iriam produzir com mais eficácia comportamentos eficazes. Para citar um exemplo trivial, podemos tentar "entender" como atingir uma bola de tênis e nos prender tanto à essas análises que teremos de ter "Aulas Internas de Tênis" para aprendermos a nos silenciar e apenas atingir a bola. Portanto, o comportamento governado por regras pode apresentar um grande impedimento ao controle pela contingência direta.

Existe quase ou nenhum freio no "diálogo interno" - isso é, falar e escutar privadamente - pois o comportamento verbal, uma vez estabelecido, não requer suporte ambiental para sua ocorrência.
Isso significa que regras estarão prontamente disponíveis para participarem no controle do nosso comportamento uma vez que tivermos adquirido comportamento verbal. É difícil imaginar como poderíamos escapar dessa forma de controle verbal uma vez que regras incorrem em custos significativos em algumas áreas. Esse frequentemente parece ser um foco central da psicoterapia.

Considere a seguinte situação, que é tirada de um pacote terapêutico conhecido como "distanciamento abrangente."? (Hayes, 1987; Hayes, Korn, Zettle, Rosenfarb, \& Cooper, 1982). Imagine que eu tenha te conectado ao melhor polígrafo do mundo, e que não há absolutamente nenhuma maneira de você ficar ansioso sem que eu saiba. Agora, suponha que sua tarefa é simplesmente relaxar - não se sentir ansioso. Para ajudar a motivá-lo a realizar essa simples tarefa eu saco uma arma e explico que enquanto você permanecer relaxado, você não levará um tiro. Em tal situação parece óbvio que você se sentirá ansioso se tentar não se sentir ansioso. Isso é, o seguimento da regra, "Custe o que custar, eu não posso ficar ansioso" é em si mesmo algo para se ficar muito ansioso. A ansiedade não se deve somente à arma pois a mesma reação seria provável se você fosse perder um milhão de dólares por ficar ansioso. O ponto é de que seguir uma regra é frequentemente contraproducente quando o que se busca é se livrar de reações autonômicas específicas, emoções ou pensamentos: tentar não perder uma ereção é uma das maneiras mais garantidas de perdê-la, tentar não pensar um pensamento cria automaticamente esse pensamento, e assim por diante (para uma análise mais completa dessa questão, ver Hayes, 1989). Essa parece ser a situação em que muitos clientes se encontram especialmente aqueles que lidam com emoções e pensamentos indesejáveis (como os agorafóbicos), que caem numa frequente e malsucedida luta para se livrar deliberadamente de certas reações (isso é, seguindo regras).

O problema é que é quase impossível uma situação como essa não gerar uma regra desse tipo. $\mathrm{O}$

7 Nota do tradutor: na época do artigo original, a Terapia de Aceitação e Compromisso (ACT) ainda estava em seus primórdios e o nome proposto na época foi Terapia do Distanciamento Abrangente. 
comportamento governado por regras pode, nessa situação, ser ineficaz (até desastroso), mas a regra está, mesmo assim, presente.

No entanto, você-como-perspectiva pode fornecer uma solução parcial. A partir da perspectiva desenvolvida aqui, o "você" socialmente-criado é diferente do conteúdo (ex., fala privada) contido em você. A partir dessa perspectiva parece mais possível ver uma regra sem ter de segui-la. Uma metáfora que frequentemente eu uso em terapia pode ajudar a explicar a questão. (As implicações da "teoria da cópia" deste exemplo devem-se ao seu uso clínico e não devem ser tomadas literalmente.) Imagine duas pessoas sentadas em frente a dois computadores idênticos. Dadas condições específicas de programação, um certo comando irá produzir um resultado. Nesse caso, imagine que o resultado apresentado na tela é "Lá no fundo você é uma pessoa ruim." Em uma situação vamos imaginar que a pessoa sentada em frente a tela está bem ciente da diferença entre ela mesma e o computador. Quando o letreiro aparece na tela pode ser interessante, algo a se levar em conta ou algo a se mostrar para outros. Provavelmente não será algo com que se terá de brigar, esconder, seguir, não seguir, e assim por diante A outra pessoa, no entanto, está completamente absorvida pela tela. $\mathrm{Na}$ verdade, como uma pessoa que se envolve por completo com um filme, ela esqueceu que existe uma diferença entre a tela e ela mesma como observadora da tela. Nessa situação o letreiro provavelmente exerce maior impacto. É algo de que se deve livrar, negar, esquecer, acreditar, e assim por diante. Em outras palavras, irá exercer controle sobre uma boa porção do comportamento.

Portanto, pode ser que o controle por regras destrutivo possa ser minado pela distinção entre você-como-perspectiva e o conteúdo ali presente. Isso é o que é reinvindicado por uma variedade de escritos místicos, que cunham esse aspecto do autoconhecimento como "o eu observador" (Deikman, 1982) ou por líderes religiosos que fazem a distinção entre a alma de uma pessoa e seu corpo, comportamento, pensamentos, e assim por diante. Foi dito que "Ao se des-identificar com sequência automáticas (de pensamentos) nós dimínuimos seus impactos e garantimos liberdade de espaço na qual podemos escolher uma resposta apropriada...Ao nos identificarmos com o eu observador, podemos fazer uma avaliação mais realista... permitindo comportamento mais eficaz e criativo (Deikman, 1982, p. 108). Apesar da linguagem mentalista, o ponto é bastante claro. $\mathrm{O}$ controle por autorregras pode ser enfraquecido ao vê-las do ponto de vista de você-como-perspectiva, e talvez comportamentos mais criativos (presumivelmente modelados pela contingência) podem, então, emergir.

Tradições místicas se orientam explicitamente em direção ao aprimoramento da distinção entre conteúdo verbal na vida das pessoas e o contexto da pura perspectiva estabelecido em organismos verbais. Talvez uma forma de pensar isso é de se pensar em um segundo tipo de comportamento modelado pelas contingências. Em organismos não-verbais, todo comportamento é modelado pelas contingências, quer na vida do indivíduo ou da espécie. Em organismos verbais, mesmos comportamentos em sua origem modelados pelas contingências podem ser descritos, rotulados, racionalizados, e assim por diante. Isso é, eventos podem adentrar em classes simbólicas (ex., equivalência) preexistentes estabelecidas pela comunidade verbal. Tais classes estão frequentemente a disposição para controlar comportamentos futuros. Outros comportamentos eram governados por regras no começo, no sentido de que eram originalmente controlados por estímulos arbitrários organizados pela comunidade verbal em classes simbólicas. Assim, nos organismos verbais, as regras passam a abranger uma boa parte do repertório comportamental disponível.

A tomada de perspectiva pura, no entanto, não envolve a tomada de perspectiva no sentindo de ter uma opinião. O comportamento não pode entrar em uma classe de equivalências (ou outras simbólicas) e ainda assim exercer sua função. Tomada de perspectiva não é uma atividade simbólica. $\mathrm{O}$ comportamento é produzido pelo comportamento verbal.

Ele pode ser pensado como um segundo tipo de comportamento puramente modelado pelas contingências - mas nesse caso as contingências são aquelas produzidas pela comunidade verbal no processo de estabelecer autoconsciência. Qualquer procedimento que decompõe a qualidade literal das regras tenderá a aumentar a saliência desse segundo tipo de comportamento em forma de contingência. 
Considere a meditação concentrativa característica, por exemplo, da Meditação Transcendental, onde um mantra é repetido por várias vezes seguidas. Assim como qualquer significado no conteúdo do mantra se quebra (por repetição e, talvez, saciação) o que sobra é mais contexto do que conteúdo. Em outros tipos de meditação, mais características da tradição Budista, uma observação imparcial de pensamentos espontâneos é estimulada. Surgem regras neste caso, mas não se reage a elas de forma alguma - o que pode se ver como um tipo de procedimento de extinção para o controle pela literalidade de falar consigo mesmo. Outros exemplos podem ser dados. Monges adentram mosteiros aonde o falar é eliminado ou amplamente restrito. Outras tradições estimulam a repetição rítmica de um canto. Em nenhuma forma de meditação, conforme geralmente se usa o termo, o meditador se empenha em um pensamento discursivo, analítico (Deikman, 1982).

Dito de outra forma, nenhuma dessas tradições estimulam o indivíduo a reagir às qualidades dos termos por sua participação em classes de equivalência, tais como "significado", "lógica" ou "referência”. O que é comum em todas essas tradições é a escolha por processos que podem enfraquecer a qualidade literal e, portanto, o controle por regra exercido por falar sozinho enquanto se aprimora a saliência de você-como-contexto.

É notável como este movimento de criar uma distinção entre conteúdo e contexto é comum dentro da psicoterapia. Beck têm seu "distanciamento" (Hollon \& Beck, 1979), por exemplo, e mesmo Freud pedia à seus clientes para adotarem uma postura de "auto-observação silenciosa e irreflexiva". (Strachey, 1964, p. 287). Portanto, embora a linguagem difira muito, o pensamento da psicoterapia ocidental guia-se (com frequência e não deliberadamente) pela distinção conteúdo/contexto.

Diz-se que a linguagem produziu a "perda da inocência" na humanidade. A história de Adão e Eva é talvez um reflexo desse pensamento. É dito por alguns que a espiritualidade reestabelece um tipo de "inocência experienciável". Como a narrativa Zen que pergunta "um cachorro tem uma natureza de Buda?" nós vemos que não podemos de fato retroceder, mas que a espiritualidade (vocêcomo-contexto) nos dá uma possível solução ao dilema. Através de um segundo tipo de comportamento modelado pelas contingências é possível enfraquecer o controle por regras automático e permitir que as contingências diretas exerçam maior controle por si só. Como um monge Oriental diz "Quando estou faminto, eu como; quando estou sonolento, eu durmo."

Em resumo, então, uma interpretação comportamentalmente sensível da espiritualidade sugere não apenas uma fonte, mas também possíveis contingências mantenedoras para uma distinção entre matéria/espírito. É possível argumentar que em tempos perigosos como esses precisamos ainda mais de um tipo de espiritualidade que permita que nosso comportamento esteja sob controle mais eficaz pelas contingências diretas. É irônico, mas a ciência e o materialismo podem fornecer uma boa racional para a utilidade funcional de aspectos do dualismo que busca suplantar.

\section{Referências}

Baron, A. \& Galizio, M. (1983). Instructional control of human operant behavior. The Psychological Record, 33, 495-520.

Deikman, A. J. (1982). The observing self Mysticism and psychotherapy. Beacon Press.

Hayes, S. C. (Ed.). (1989). Rule-governed behavior: Cognition, contingencies, and

instructional control. Plenum.

Hayes, S. C. (1987). A contextual approach to therapeutic change. In N. Jacobson (Ed.),

Psychotherapists in clinical practice: Cognitive and behavioral perspectives. Guilford.

Hayes, S. C., Brownstein, A. J., Zettle, R. D., Rosenfarb, I., \& Korn, Z. (1986). Rule-governed behavior and insensitivity to rapidly changing contingencies. Journal of the Experimental Analysis of Behavior. https://doi.org/10.1901/ jeab.1986.45-237

Hayes, S. C., Greenway, D., Brownstein, A. J., Haas, J., Russell, F., Squittiere, D. C., Rosenfarb, I., Zettle, R. D., Herbert, J. D., Herbert, D. L., Meinhold, P., \& Thompson, S. K. (1984). Rules, multiples schedules, and extinction. Paper presented at the Association for Behavior Analysis, Nashville. 
Hayes, S. C. \& Maley, R. F. (1977). Coercion: Legal and behavioral issues. Behaviorism, 5, 95-97.

Hayes, S. C., Korn, Z., Zettle, R. D., Rosenfarb, I., \& Cooper, L. (1982). Rule-governed behavior and cognitive behavior therapy: The effects of comprehensive distancing on pain tolerance. Paper presented at the meeting of the Association for Advancement of Behavior Therapy, Los Angeles.

Hineline, P. (1980). The language of behavior analysis: Its community, its functions, and its limitations. Behaviorism, 8, 67-85.

Hollon, S. D., \& Beck, A. T. (1979). Cognitive therapy of depression. In P. C. Kendall \& S. D. Hollon (Eds.), Cognitive-behavioral interventions: Therapy, research, and procedures. Academic Press. https://doi.org/10.1016/b9780-12-404480-7.50012-5

Matthews, B. A., Shimoff, E., Catania, A. C., \& Sagvolden, T. (1977). Uninstructed human

responding: Sensitivity to ratio and interval contingencies. Journal of the Experimental Analysis of Behavior, 27, 453-467. https://doi.org/10.1901/ jeab.1977.27-453

Olson, T. W. \& Hayes, S. C. (1984). Effect of rulespecificity on sensitivity to changing contingencies. Paper presented at the meeting of the Association for Behavior Analysis, Nashville.

Schoenfeld, W. N. (1979). Religion and human behavior. Invited address at the meeting of the American Psychological Association, New York.

Shimoff, E., Catania, A. C., \& Matthews, B. A. (1981). Uninstructed human responding: Responsivity of low-rate performance to schedule contingencies. Journal of the ExperimentalAnalysis of Behavior, 36. 207-220. https://doi.org/10.1901/jeab.1981.36-207

Sidman, M. (1971). Reading and auditory-visual equivalences. Journal of Speech and Hearing Research, 14, 5-13. https://doi.org/10.1044/ jshr.1401.05

Sidman, M., \& Cresson, O., Jr. (1973). Reading and cross-modal transfer of stimulus equivalences in severe retardation. American Journal o' Mental Deficiency, 77, 515-523.

Skinner, B. F. (1945). The operational analysis of psychological terms. Psychological Review, 52, 270-277. https://doi.org/10.1037/h0062535
Skinner, B. F. (1953). Science and human behavior. MacMillan.

Skinner, B. F. (1974). About behaviorism. Knopf. Strachey, J. (Ed). (1964). The standard edition of the complete psychological works of Sigmund Freud. Vol. 16. Hogarth Press.

\section{Informações do Artigo}

Histórico do artigo:

Tradução submetida em: 19/10/2018

Aceito em: 09/12/2019 